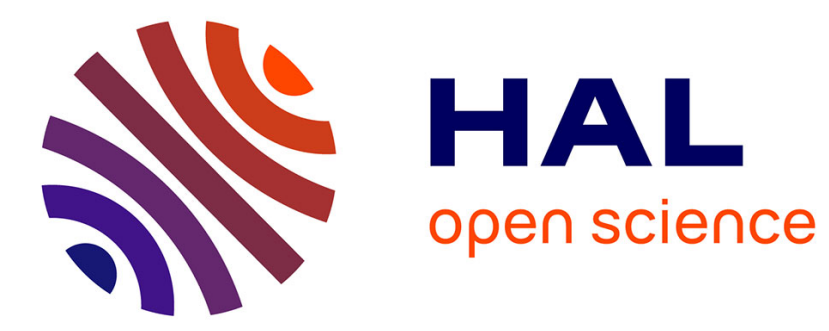

\title{
Molecular engineering of dendrimer nanovectors for siRNA delivery and gene silencing
}

\author{
Yu Cao, Xiaoxuan Liu, Ling Peng
}

\section{To cite this version:}

Yu Cao, Xiaoxuan Liu, Ling Peng. Molecular engineering of dendrimer nanovectors for siRNA delivery and gene silencing. Frontiers of Chemical Science and Engineering, 2017, 11 (4), pp.663 - 675. 10.1007/s11705-017-1623-5 . hal-01962995

\section{HAL Id: hal-01962995 \\ https://hal.science/hal-01962995}

Submitted on 18 Nov 2020

HAL is a multi-disciplinary open access archive for the deposit and dissemination of scientific research documents, whether they are published or not. The documents may come from teaching and research institutions in France or abroad, or from public or private research centers.
L'archive ouverte pluridisciplinaire HAL, est destinée au dépôt et à la diffusion de documents scientifiques de niveau recherche, publiés ou non, émanant des établissements d'enseignement et de recherche français ou étrangers, des laboratoires publics ou privés. 


\title{
Molecular engineering of dendrimer nanovectors for siRNA delivery
}

\author{
Yu Cao ${ }^{a}$ Xiaoxuan Liu, ${ }^{b}$ Ling Peng ${ }^{a, *}$
}

\begin{abstract}
a Aix-Marseille Université, CNRS, Centre Interdisciplinaire de Nanoscience de Marseille, UMR 7325, « Equipe Labellisée Ligue Contre le Cancer », 13288 Marseille, France

${ }^{b}$ State Key Laboratory of Natural Medicines and Jiangsu Key Laboratory of Drug Discovery for Metabolic Diseases, Center of Drug Discovery, China Pharmaceutical University, 210009 Nanjing, China
\end{abstract}

Address correspondence to:

Ling Peng, Ph.D.

ling.peng@univ-amu.fr 


\begin{abstract}
Small interfering RNA (siRNA) therapeutics hold great promise to treat a variety of diseases, as long as they can be delivered safely and effectively into cells. Dendrimers are appealing vectors for siRNA delivery by virtue of their well-defined molecular architecture and multivalent cooperativity. However, the clinical translation of RNA therapeutics mediated by dendrimer delivery is hampered by the lack of dendrimers that are of high quality to meet good manufacturing practice (GMP) standard. In this context, we have developed small amphiphilic dendrimers that self-assemble into supramolecular structures, which mimic high-generation dendrimers synthesized with covalent construction, yet are easy to produce in large amount and superior quality. Indeed, the concept of supramolecular dendrimers has proved to be very promising, and has opened up a new avenue for dendrimer-mediated siRNA delivery. A series of self-assembling supramolecular dendrimers have consequently been established, some of them out-performing the currently available nonviral vectors in delivering siRNA to various cell types in vitro and in vivo, including human primary cells and stem cells. This short review presents a brief introduction to RNAi therapeutics, the obstacles to their delivery and the advantages of dendrimer delivery vectors as well as our bio-inspired structurally flexible dendrimers for siRNA delivery. We then highlight our efforts in creating self-assembling amphiphilic dendrimers to construct supramolecular dendrimer nanosystems for effective siRNA delivery as well as the related structural alterations to enhance delivery efficiency. The advent of self-assembling supramolecular dendrimer nanovectors holds great promise and heralds a new era of dendrimer-mediated delivery of RNA therapeutics in biomedical applications.
\end{abstract}




\section{RNA interference and siRNA therapeutics}

RNA therapeutics based on RNA interference (RNAi) provide an enormous opportunity for treating a variety of diseases by virtue of the ability of small interfering RNA (siRNA) to turn off the expression of specific disease-related genes [1-4]. RNAi is a sequence-specific gene silencing mechanism triggered by siRNA (Figure 1) [5,6]. It was discovered in 1998 by Fire and Mello et al [5], who were consequently awarded the Nobel Prize in 2006. The natural RNAi process involves the cleavage of endogenous long double-stranded RNAs into short siRNAs ( 21-23 nucleotides in length) by the Dicer endonuclease [6]. The resulting siRNA is then incorporated into the multiprotein RNA-induced silencing complex (RISC). The doublestranded siRNA is subsequently unwound, with the sense or "passenger" strand being degraded while the antisense or "guide" strand targets the 3' end of mRNA transcripts through complementary Watson-Crick base-pairing. The mRNA is then degraded by the endonuclease activity of Argonaute 2 (Ago2), a RISC subunit, preventing translation of the mRNA into protein, and hence resulting in gene silencing (Figure 1) [7]. Following the degradation of the target mRNA, the activated RISC complex is regenerated and can then mediate further cycles of mRNA binding and cleavage [8]. 


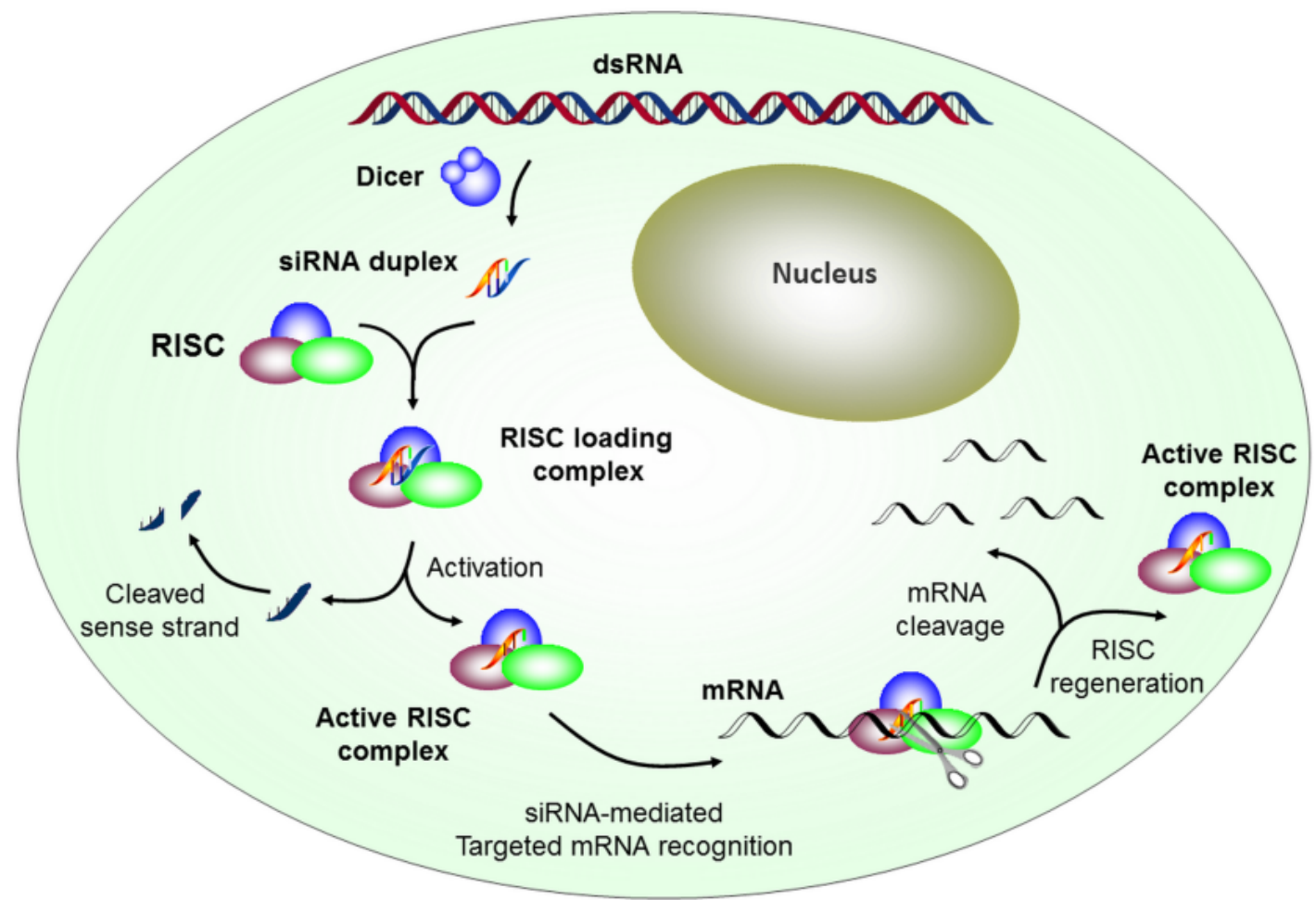

Figure 1: The mechanism of RNA interference. Silencing is triggered by long double-stranded RNAs, which are recognized and processed into small interfering RNAs (siRNAs) by the enzyme Dicer. The duplex siRNAs are then passed to the RISC (RNA-induced silencing complex), which is activated by unwinding of the siRNA. The sense strand of the siRNA is cleaved and discarded, while the antisense strand remains associated with the active RISC complex, guiding it to a target mRNA containing a complementary sequence. The complex then cleaves the mRNA, resulting in silencing of the targeted gene. The RISC can destroy multiple identical transcripts by undergoing further catalytic cycles of binding and cleavage of target mRNAs.

Synthetic siRNAs can be designed to be complementary to any gene for which the sequence is available, and can therefore be applied to target and down-regulate disease genes for therapeutic purposes [1-4]. By virtue of the catalytic nature of the RNAi mechanism, siRNAs have a stronger and more prolonged therapeutic effect when compared with antisense oligonucleotides and ribozymes. The potential of siRNA to catalyze the specific downregulation of any disease gene with known sequence has opened up a new era of RNA 
therapeutics, which has the potential to revolutionize the treatment of many diseases, including those that are incurable or difficult to treat because of drug resistance, or the absence of effective drugs or druggable targets.

\section{Challenges to siRNA delivery}

Based on the RNAi mechanism, siRNA molecules targeting specific disease-related genes with known sequences can be easily devised according to Watson-Crick base-pairing and then synthesized readily according to good manufacturing practice (GMP) standards as therapeutic agents. However, naked siRNAs are not suitable for therapeutic administration because they are not stable and can be rapidly degraded by enzymes such as nucleases and esterases that are present in the body. Furthermore, siRNAs are highly anionic hydrophilic molecules with a molecular weight over 12000 Daltons, and therefore cannot readily cross biological membranes to enter into cells. Consequently, there is a high demand for safe and efficient delivery systems, which can protect the siRNA cargo from degradation, shield the high density of negative charges, convey the siRNA to the site of interest, and enter into cells.

Both viral and nonviral vectors have been explored for siRNA delivery, and viral vectors are currently the most effective. However, growing concerns over the safety and immunogenicity of viral vectors have resulted in enormous efforts over the last decade to develop nonviral vectors for siRNA delivery [9-11]. These efforts have given rise to a variety of novel synthetic vectors composed of lipids, polymers, and inorganic materials such as carbon nanotubes, gold nanoparticles and quantum dots. To be effective for siRNA delivery, an ideal delivery vector must fulfil four main criteria. Firstly, it must be able to shelter the siRNA from degradation in the bloodstream. Secondly, it must be able to deliver the siRNA specifically to the target site, in order to avoid unwanted side-effects from nonspecific delivery. Thirdly, the vector must have the ability to promote cell uptake and to escape from endosomes once inside the cell. Finally, the carrier must release the siRNA efficiently so that it can interact with the RISC and activate the RNAi mechanism to effectively silence the target gene (Figure 2). The major disadvantage of nonviral carriers is that their delivery efficiency is much lower than viral vectors. Therefore, a great endeavour has been directed to develop nonviral carriers with better 
transfection efficiency.

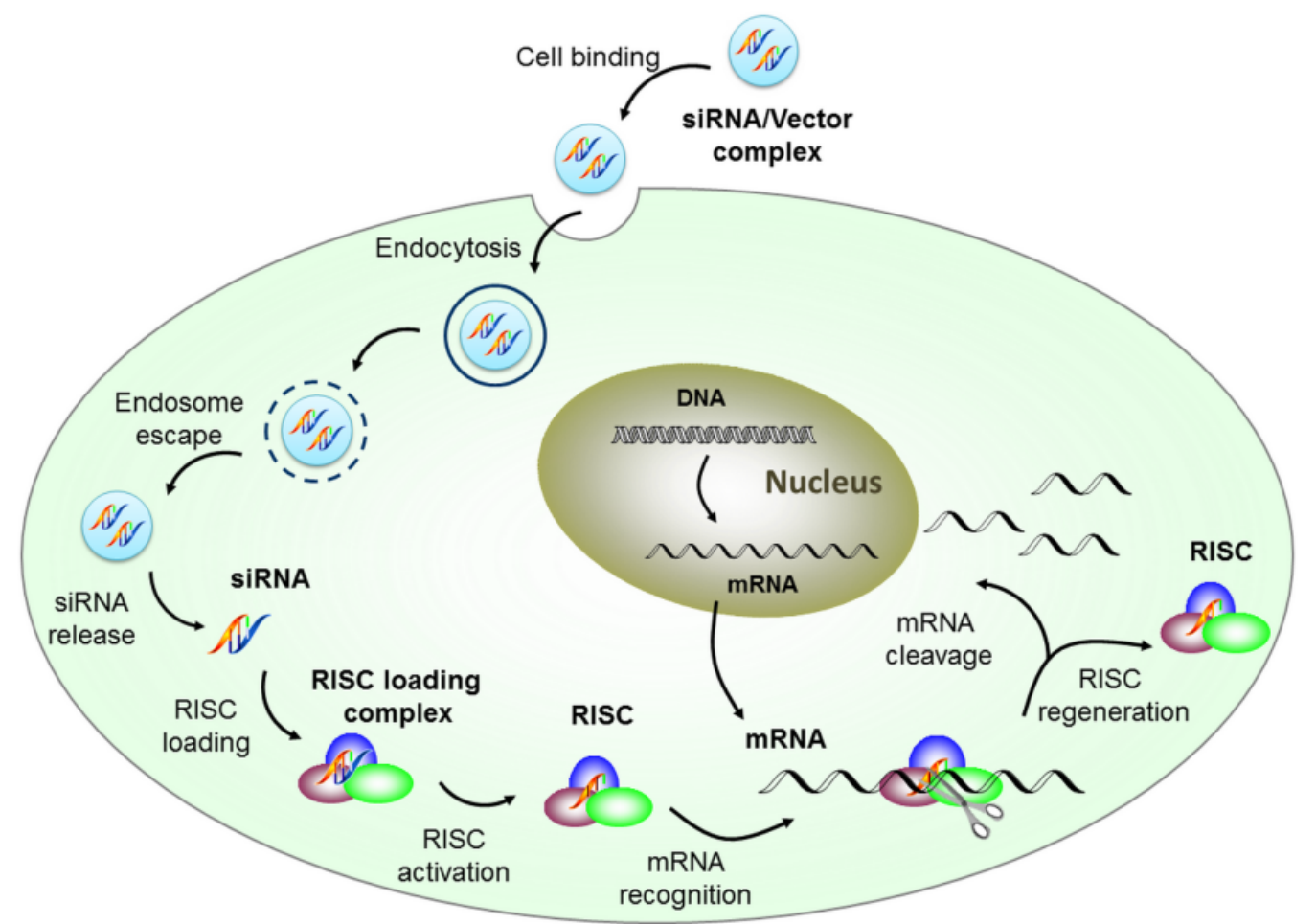

Figure 2: Nonviral vector-mediated siRNA delivery and gene silencing.

\section{Dendrimers for siRNA delivery}

Among the various nonviral vectors, dendrimers, a special class of synthetic polymers characterized by a distinct ramified molecular architecture and unique multivalence, represent a promising delivery platform for siRNA therapeutics $[12,13]$. They differ from traditional polymer vectors in that they possess a well-defined structure with three distinct structural domains (Figure 3): (i) a central core, where dendrimer growth begins; (ii) branching units which allow dendrimer growth in geometrically organized radial layers known as generations (G); and (iii) an abundance of terminal functionalities on the surface, which confer specific properties along with multivalent cooperativity on the dendrimer [14]. It is worth mentioning that the central core itself is generation $0\left(\mathrm{G}_{0}\right)$, while generation $1\left(\mathrm{G}_{1}\right)$, generation $2\left(\mathrm{G}_{2}\right)$ and generation $3\left(\mathrm{G}_{3}\right)$ refer to dendrimers with the first, second and third levels of branching, respectively (Figure 3). In addition, the structure of a dendrimer can be controlled with precision during the stepwise synthesis process, which can be carried out via either a divergent 
strategy or a convergent strategy or a combination of both $[14,15]$. These unique features make dendrimers distinctly different from linear and hyperbranched polymers.

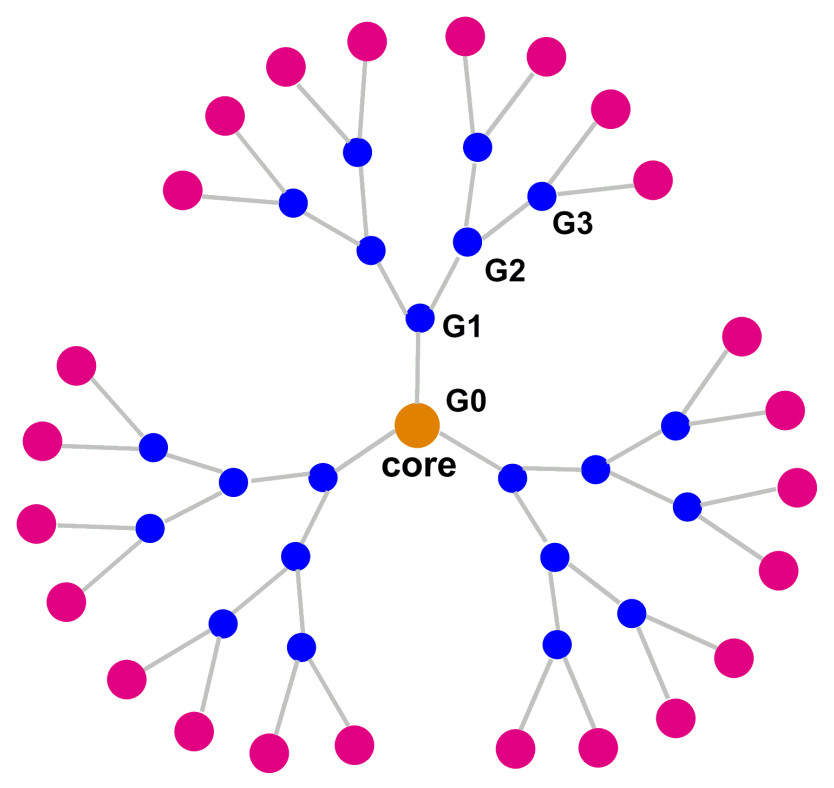

Figure 3: General presentation of the structure of a dendrimer, which is composed of a central core, the repetitive branching units which form the generations and the terminal groups. The central core itself is generation $0\left(\mathrm{G}_{0}\right)$; generation $1\left(\mathrm{G}_{1}\right)$, generation $2\left(\mathrm{G}_{2}\right)$ and generation 3 $\left(\mathrm{G}_{3}\right)$ refer to dendrimers with the first, second and third levels of branching, respectively.

To date, a multitude of dendrimers have been investigated to for their potential in siRNA delivery. Among them, poly(amidoamine) dendrimers, also called PAMAM dendrimers (Figure 4) have been the most extensively explored. PAMAM dendrimers were initially synthesized as protein mimics by Tomalia and co-workers in 1985 [16], and have since been widely studied as nonviral vectors for DNA delivery [17-21]. These dendrimers terminate with primary amine groups, and are therefore positively charged at physiological $\mathrm{pH}$ (7.4). Consequently, PAMAM dendrimers can readily condense polyanionic nucleic acids into dendriplexes via electrostatic interactions. Another important feature of PAMAM dendrimers is that they contain tertiary amines in their interior structure, which can mediate the "proton sponge" effect in acidic intracellular vesicles (endosomes and lysosomes). Protonation of tertiary amines is thought to lead to osmotic imbalance, causing rupture of the endosomal vesicles, disassembly of the dendriplexes, and release of the nucleic acid cargo into the 
cytoplasm [22]. Following release, the nucleic acid molecules will eventually enter into the nucleus for DNA transfection or engage with the RNAi machinery to activate the RISC for gene silencing.

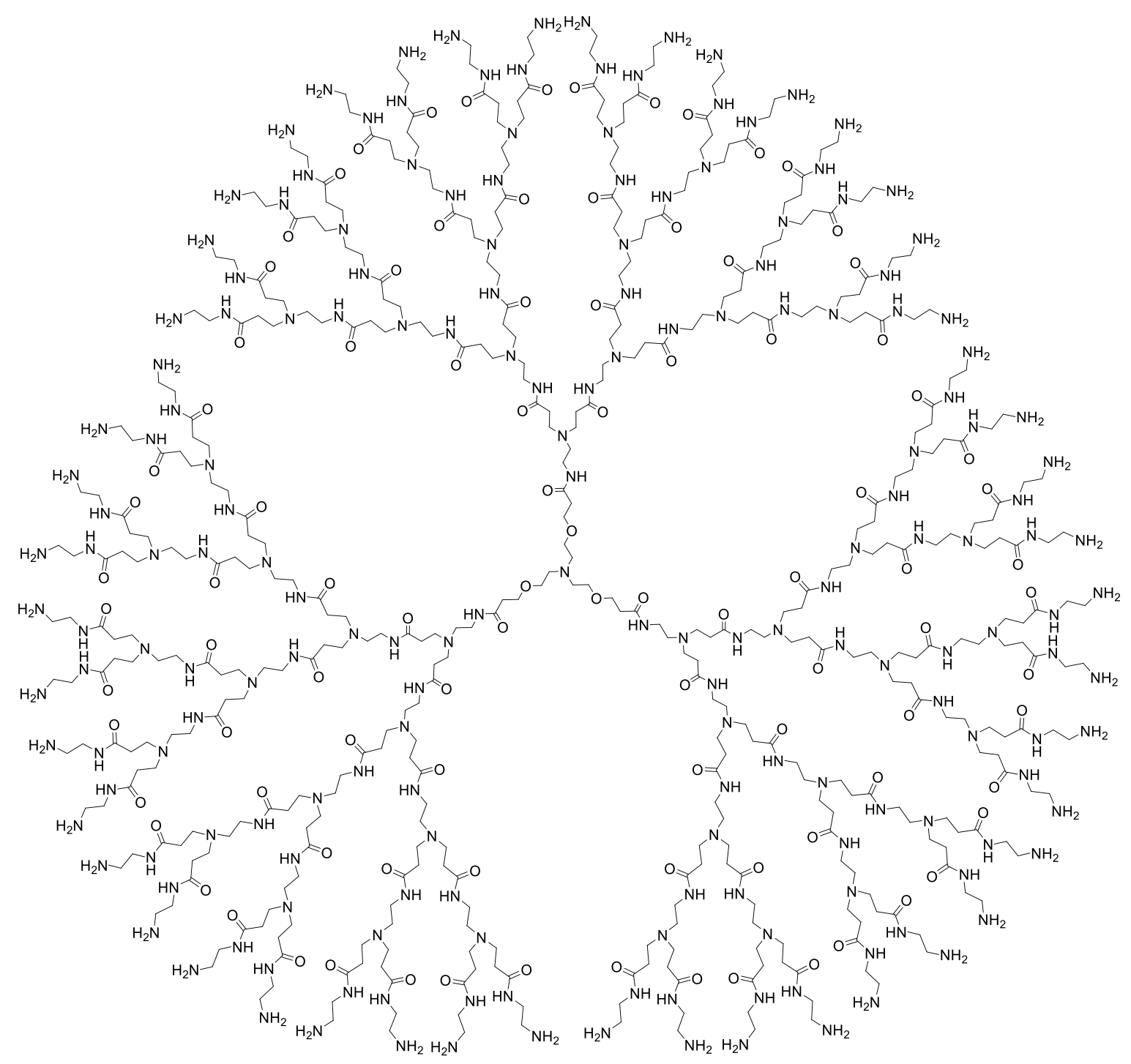

Figure 4: Molecular structure of a PAMAM dendrimer with a triethanolamine (TEA) core. For clarity, only a generation 4 dendrimer is presented.

Although PAMAM dendrimers have been widely studied as nonviral vectors for DNA delivery $[17,18,20,21]$, in the past decade they have also been investigated as siRNA carriers $[12,23,24]$. In 2005 , Juliano et al. tested the siRNA delivery properties of a commercially 
available PAMAM dendrimer with an ethylenediamine (EDA) core [25]. Neither the dendrimer itself nor its conjugates were effective for siRNA delivery and gene silencing. Soon afterwards, in 2006, we developed structurally flexible PAMAM dendrimers and used them achieve effective siRNA delivery and successful gene silencing [26]. These structurally flexible dendrimers [27] were conceived by inspiration from the histone, which has dynamic structure via conformational change when binds to DNA for post translational modification while dissemble DNA to prevent transcription [28]. The devised dendrimers have an extended triethanolamine (TEA) core (Figure 4) [27], which endows the dendrimers with more internal space to accommodate the branching units, thereby imparting structural flexibility to the resulting dendrimers [29]. In other words, the branching units in TEA-core-based dendrimers are less densely packed, which means that the dendrimers are more accessible to water and nucleic acids and thus have enhanced nucleic acid binding and release properties [29-31]. Indeed, our structurally flexible TEA-core dendrimers are able to bind siRNA to form stable and uniform nanoparticles with a size of $\sim 70 \mathrm{~nm}$ [32], which can effectively protect the siRNA from degradation and facilitate cellular uptake of siRNA via endocytosis, preferentially macropinocytosis (Figure 5) [30]. After entering a cell, the siRNA molecules can escape from the endosome through swelling and breakage of the siRNA/dendrimer complexes, which is promoted by the "proton sponge" effect as described above. Consequently, these PAMAM dendrimers make excellent vectors for delivering RNA therapeutics in various disease models such as prostate cancer [30,31,33-35], liver cancer [36], ovarian cancer [37], glioblastoma [38,39] and HIV infection [40] etc. One of our dendrimers, the generation 5 of TEA-core PAMAM dendrimer, was scheduled for clinical trial for cancer therapy [23]. Unfortunately, due to the lack of GMP dendrimer, the clinical trial was delayed and finally modified with the use of Smarticles $^{\mathrm{R}}$ to replace the dendrimer for delivery of the RNA therapeutics (https://clinicaltrials.gov/ct2/show/NCT02716012). 


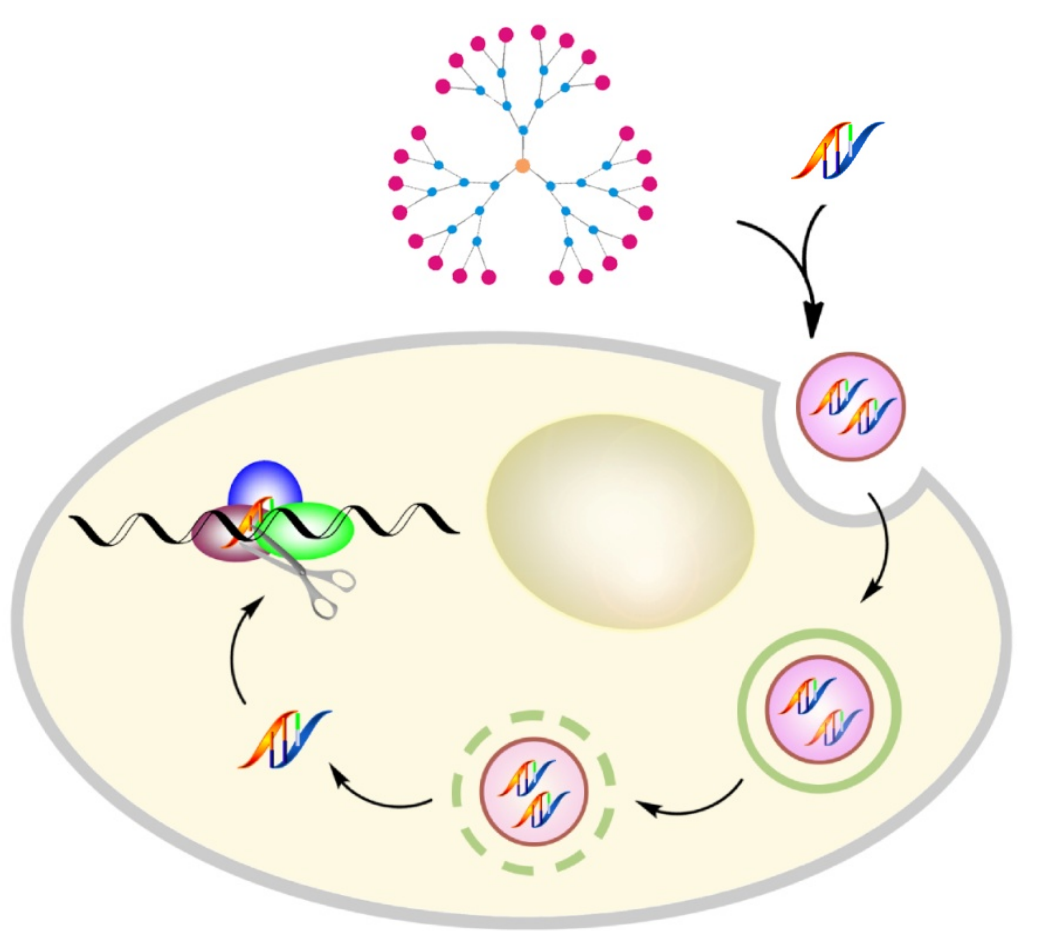

Figure 5: Cartoon presentation of siRNA delivery mediated by a dendrimer.

It should be mentioned that dendrimer synthesis is by no means trivial, but is instead rather tedious, time-consuming and laborious. Different from conventional polymers, which are created by one-pot synthesis, the construction of dendrimers is achieved via stepwise synthesis, similar to that of small molecules. However, unlike small molecules, dendrimer purification is difficult and complicated due to the presence of highly similar side-products [41]. This situation gets even worse when preparing higher generation dendrimers. All these issues mean that the large-scale production of GMP-standard high-generation dendrimers is technically challenging, which impedes the clinical translation of dendrimer-based therapeutic interventions [41].

\section{Self-assembling supramolecular dendrimer vectors}

Since GMP production of high-generation PAMAM dendrimers is challenging, it is desirable and preferable to explore small, easy-to-synthesize low-generation dendrimers for siRNA delivery. We then came up with the idea of using small amphiphilic dendrimers [42] to create large supramolecular dendrimers through self-assembly (Figure 6A) [43], in the hope that these 
non-covalently-created supramolecular dendrimers could mimic the covalently-constructed high-generation dendrimers in size, structure and function - in particular, for siRNA delivery.

A
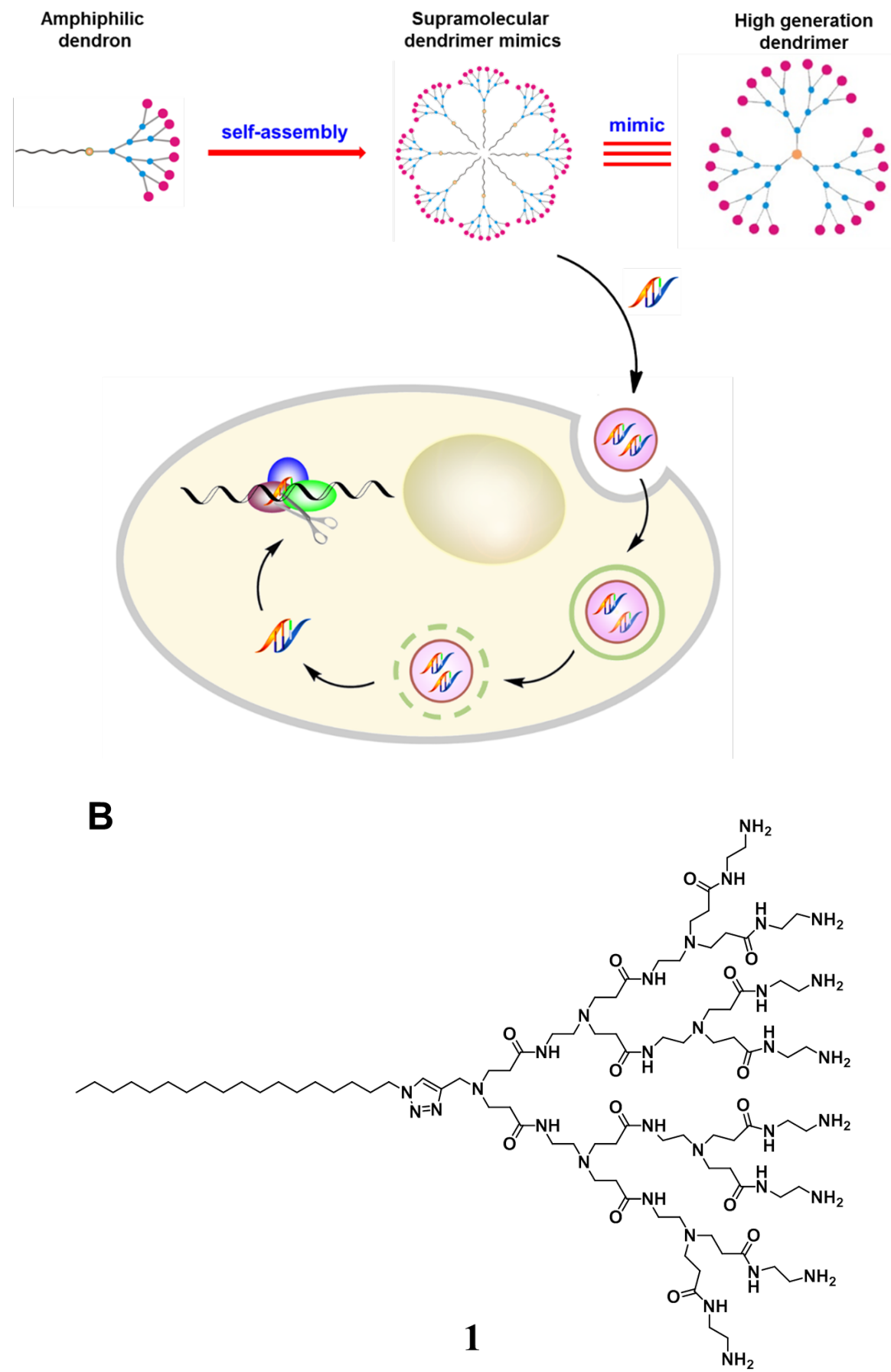

Figure 6. (A) Self-assembly of a small amphiphilic dendrimer to create a supramolecular dendrimer that mimics a covalently synthesized high-generation dendrimer for siRNA delivery [43]; (B) Amphiphilic dendrimer 1, carrying a hydrophobic C18 alkyl chain and a hydrophilic PAMAM dendron with 8 terminal amine groups [42]. 
With this in mind, we developed an amphiphilic dendrimer (1) bearing a hydrophobic C18 alkyl chain and a hydrophilic PAMAM dendron with 8 amine terminals (Figure 6B) [42]. This dendrimer self-assembles into nanoparticles with a size of $\sim 7.0 \mathrm{~nm}$ [43], which is in the range of typical nanomicelles. Remarkably, the dimensions of these self-assembled nanomicelles are similar to those of high-generation structurally flexible TEA-core dendrimers [29]. This suggests that the nanostructures generated by self-assembly of low-generation dendrimers are structural mimics of traditional covalently synthesized high-generation dendrimers (Figure 6A). Most importantly, this supramolecular dendrimer mimic has been shown to deliver siRNA effectively to various cell types, leading to potent gene silencing in vitro and in vivo $[42,43]$.

It is noteworthy that small PAMAM dendrimers either without a hydrophobic chain or with a hydrophilic PEG chain (2 and $\mathbf{3}$ in Figure 7) are devoid of amphiphilic character and cannot form micellar supramolecular dendrimers for siRNA delivery [43]. These results can be ascribed to the intrinsic incapacity of these dendrimers to self-assemble into robust supramolecular structures that mimic high-generation dendrimers. Thus, the presence of the positively-charged dendron structure by itself is insufficient for effective siRNA delivery.

Furthermore, amphiphilic dendrimers with either lower generation dendrons [42] (4 and 5 in Figure 7) or shorter alkyl chains [43] (6 and 7 in Figure 7) also failed to generate notable gene silencing. This highlights that both the size of the PAMAM dendron and the length of the alkyl chain have an important effect on the delivery efficiency [43,44]. If the generation number is too low (as with $\mathbf{4}$ and 5), the multivalency will be small and the dendrimers will not be able to form a strong electrostatic interaction with siRNA molecules. If the alkyl chain length is too short (as with 6 and 7), the ability to form hydrophobic interactions will be weak and the molecules will not be able to self-assemble into stable supramolecular dendrimers for effective siRNA delivery. 

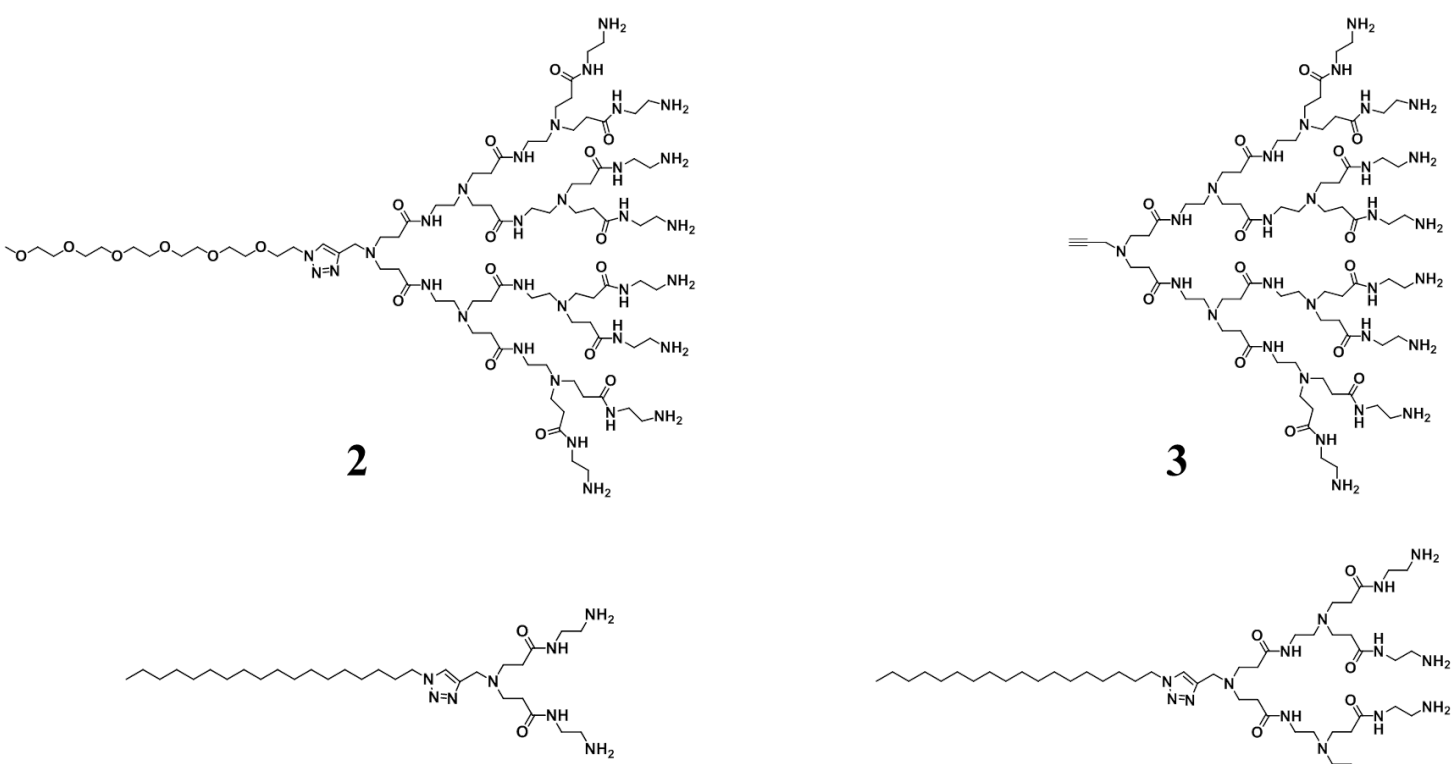

4
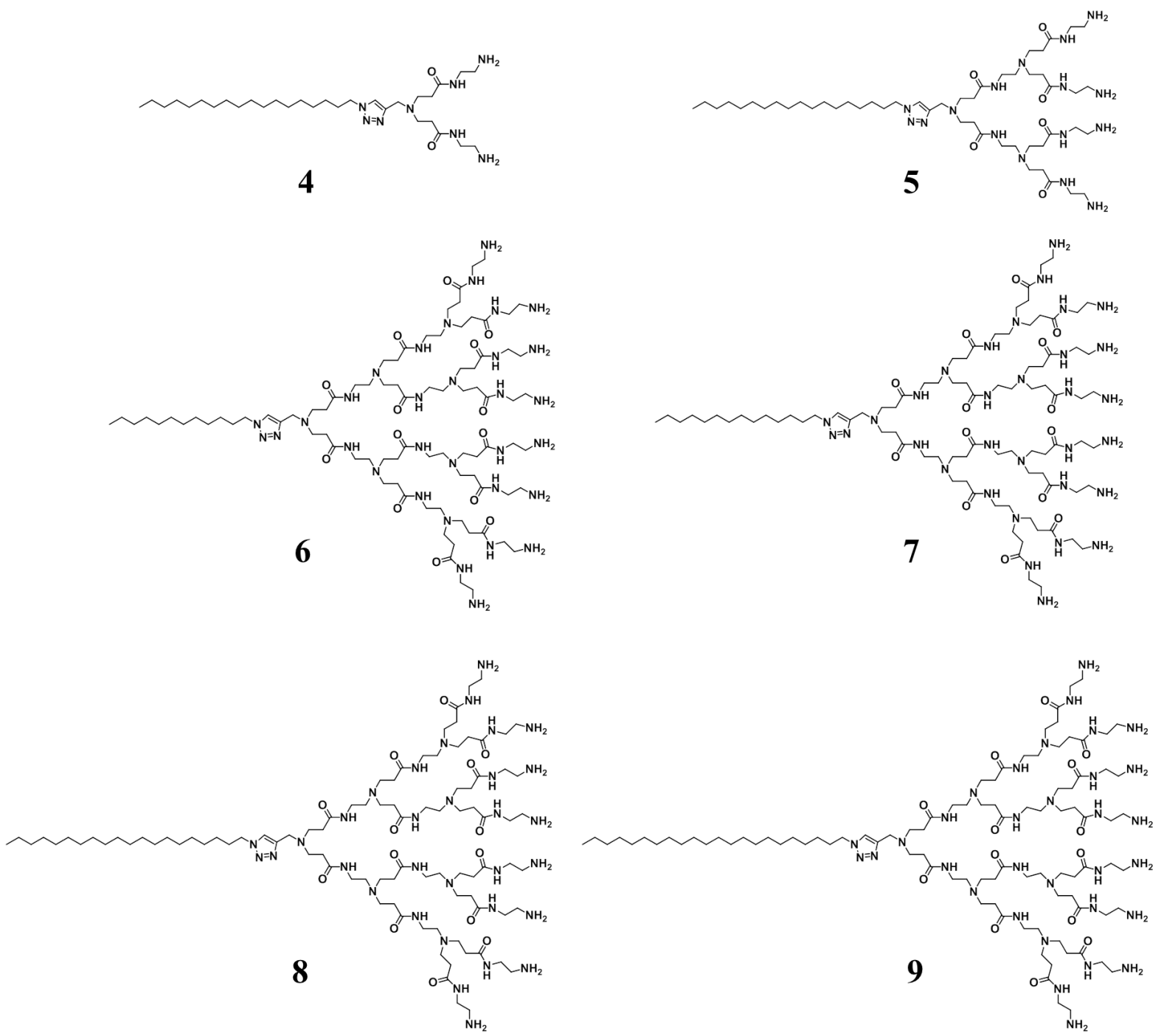

Figure 7. Structural derivatives of the amphiphilic dendrimer $1[42,43]$.

Interestingly, PAMAM dendrimers containing longer hydrophobic tails (8 and $\mathbf{9}$ in Figure 7) were less effective for siRNA delivery, although both $\mathbf{8}$ and $\mathbf{9}$ are able to form more stable and more robust nanomicellar supramolecular dendrimers than 1 [43]. This is because the 
stable supramolecular dendrimers generated with $\mathbf{8}$ or $\mathbf{9}$ form complexes with siRNA which are too compact and stable to disassemble, thus impeding intracellular siRNA release and thereby reducing the efficiency of gene silencing. Therefore, it is important to balance the length of the hydrophobic chain and the generation number of the hydrophilic dendritic entity in order to ensure the ideal properties for self-assembly into supramolecular nanostructures to achieve effective gene silencing. The self-assembled supramolecular dendrimers formed by $\mathbf{1}$ possess the best possible siRNA binding strength alongside the best possible capacity for releasing siRNA. These combined properties allow the resulting supramolecular dendrimer to transport the siRNA through the circulatory system, then enter the target cell and deliver the siRNA cargo to the RNAi machinery for siRNA-mediated gene silencing.

In order to further enhance the delivery efficiency, we conjugated 1 with arginine to create an arginine-terminated dendrimer 10 (Figure 8), with the aim of capitalizing on the cellpenetrating advantages of arginine-rich motifs for siRNA delivery [45]. It is well known that cell-penetrating peptides bearing arginine-rich motifs can favorably promote cellular uptake [46]. This is because under physiological conditions ( $\mathrm{pH}$ 7.4), each arginine residue harbors a positively-charged primary amine group and a positively-charged guanidinium moiety. These two groups can interact with negatively-charged components of the plasma membrane, including proteoglycans and the phosphate groups in lipids, to facilitate membrane penetration. In addition, arginine residues can interact with cell membranes through divalent $\mathrm{H}$-bonding of the guanidinium moiety with the phosphate/carboxylate/sulfate groups on the cell surface. We hence reasoned that adding arginine residues to the termini of our dendrimer might also improve cell penetration and cellular uptake of the siRNA/dendrimer complexes. Indeed, compared to the corresponding non-arginine counterpart $\mathbf{1}$, dendrimer $\mathbf{1 0}$ shows significantly enhanced cell uptake of siRNA, leading to more efficient siRNA delivery and better gene silencing in different human cell types such as the prostate cancer cell line PC-3 and hematopoietic CD34 ${ }^{+}$stem cells [45]. This work highlights that addition of arginine residues to the amphiphilic dendrimer surface is a useful strategy to increase the efficiency of siRNA delivery. 


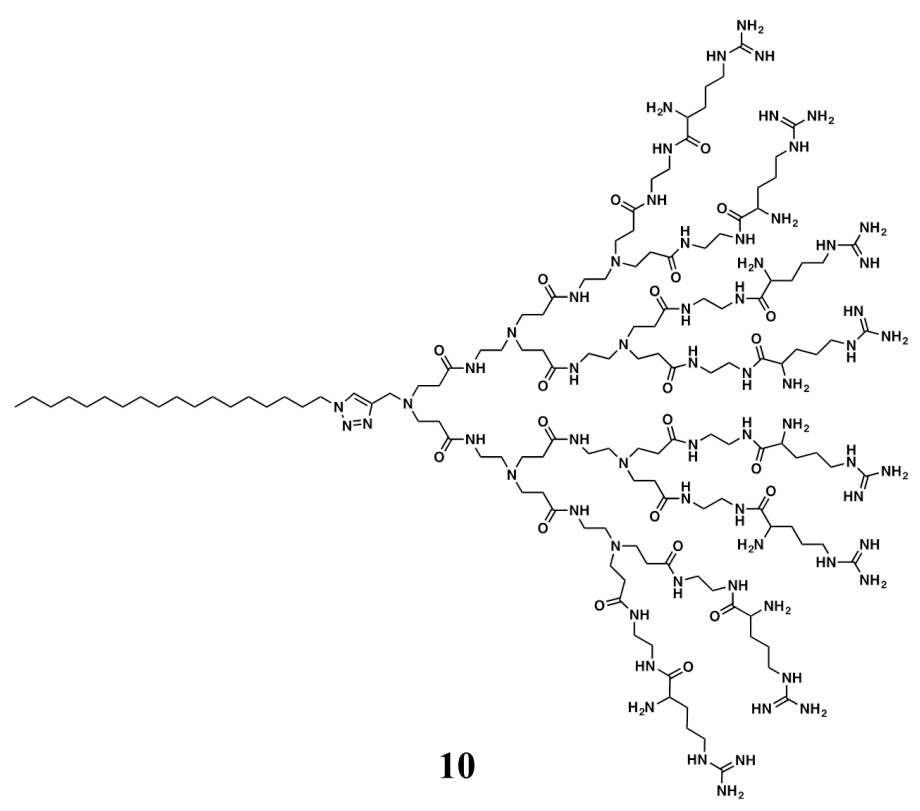

Figure 8. Arginine-terminated amphiphilic dendrimer $\mathbf{1 0}$ to enhance cellular uptake for more efficient siRNA delivery [45].

In another strategy to improve siRNA delivery, we modified the hydrophobic entity of 1 by appending two hydrophobic C18 alkyl chains, leading to the amphiphilic dendrimer 11 (Figure 9A) [47]. Interestingly, this dendrimer spontaneously self-assembled into vesicle-like dendrimersome nanostructures [48] (Figure 9B) instead of the micellar structures as formed by 1. This finding is somewhat reminiscent of lipids and detergents, with lipids often generating vesicular structures while detergents preferentally form micelles. Most importantly, the vesicle-like dendrimersomes formed by $\mathbf{1 1}$ are able to undergo concurrent structural rearrangement into small, spherical micelles upon interaction with siRNA (Figure 9B). This vesicular-to-micellar structural transition will allow 11 to maximally expose its positivelycharged terminal groups and form stronger electrostatic interactions with the anionic phosphate groups of siRNA. This will effectively entrap and condense siRNA into stable nanoparticles in order to shelter siRNA from degradation and deliver it to the desired site. In addition, the dendrimersomes formed by $\mathbf{1 1}$ are able to harness the delivery advantages of both lipid and dendrimer vectors, and are largely better than other existing nonviral vectors for delivering siRNA to a variety of different cell types in vitro and in vivo [47]. This system is also effective for targeting human primary cells and stem cells, which are highly challenging cell types for siRNA delivery. Thus, $\mathbf{1 1}$ has the unique ability to undergo dynamic self-assembly and 
rearrangement in the presence of siRNA to form adaptive supramolecular assemblies which combine the advantageous features of both lipid- and polymer-based vectors. These properties of 11, together with the fact that it is easy to synthesize, hold great promise for highly effective delivery of siRNA to a wide variety of cell types.
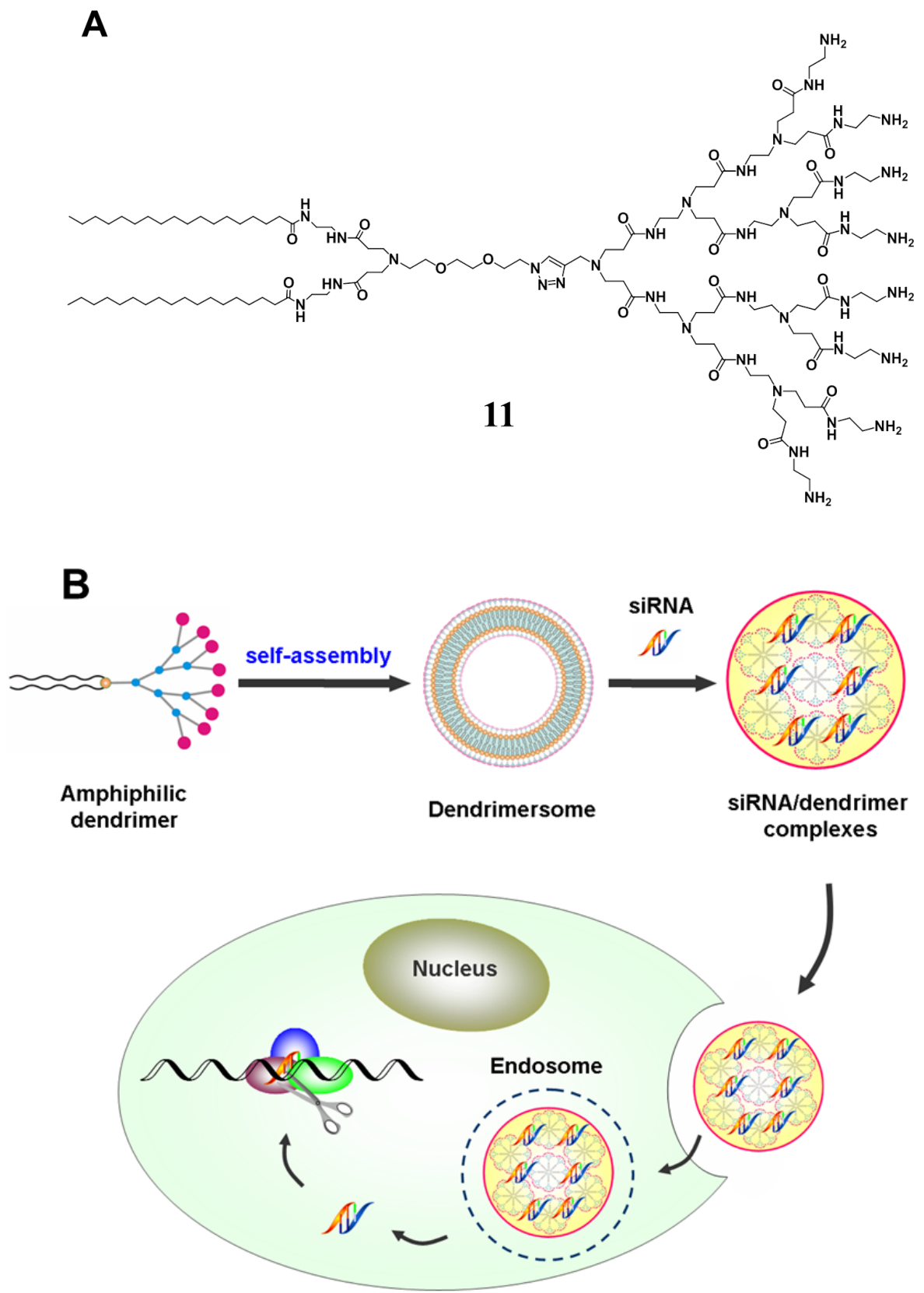

Figure 9: (A) Amphiphilic dendrimer 11 bearing two hydrophobic alkyl chains and a hydrophilic PAMAM dendron: (B) 11 forms dendrimersomes, which upon addition of siRNA, undergo spontaneous rearrangement into micelles, in order to provide maximal exposure of the positively-charged dendrimer terminals for interaction with the negatively-charged siRNA [47]. 
In our further effort to develop novel amphiphilic dendrimers for specific siRNA delivery, we have established a fluorinated bola-amphiphilic dendrimer for on-demand delivery of siRNA in response to the high level of reactive oxygen species (ROS) in cancer cells (Figure 10) [49]. ROS are constantly generated within cancer cells because of the highly stressful environment caused by rapid and uncontrollable cancer cell proliferation [50,51]. We capitalized on this characteristic feature of cancer cells to develop ROS-triggered specific delivery of siRNA. The bola-amphiphilic dendrimer 12 features a bola-lipid/dendrimer hybrid harboring a ROS-sensitive thioacetal functionality at the central core and two hydrophilic PAMAM dendrons at the terminals. The hydrophobic "bola-lipid" core scaffold is designed to mimic the robust and strong assembly properties of bola-amphiphiles observed in extremophile archaebacterial [52], whereas the two PAMAM dendrons interact with the siRNA and compact it into nanoparticles to protect it and promote its cellular uptake. In the presence of ROS, the thioacetal entity in the bola core is decomposed effectively, concurrently promoting siRNA unpacking for siRNA delivery and potent gene silencing in ROS-abundant cancer cells [49]. In addition, the hydrophobic bola-core in $\mathbf{1 2}$ is shorter than the native phospholipid bilayer, which can prevent the insertion of $\mathbf{1 2}$ into the cell membrane, thus obviating deleterious effects on cell membrane integrity and cell viability. Indeed, $\mathbf{1 2}$ is devoid of serum hemolysis and cytotoxic effects. This work represents the first report on a bola-amphiphilic dendrimer for ondemand siRNA delivery in response to ROS in cancer cells. Also of note is the presence of fluorine tags within this dendrimer, allowing the tracking of the ROS-responsive delivery process using ${ }^{19} \mathrm{~F}$ high-resolution magic angle spinning nuclear magnetic resonance (HRMAS NMR) [49]. ${ }^{19} \mathrm{~F}$ HRMAS NMR is a sensitive, non-invasive technique for analyzing ${ }^{19} \mathrm{~F}$ containing molecules in intact cells, and is ideal for tracking fluorinated $\mathbf{1 2}$ because there are no endogenous intracellular fluorinated compounds, which means that the background ${ }^{19} \mathrm{~F}$ NMR signal is minimized [53]. This study also opens a new perspective on the development of fluorinated dendrimers for ${ }^{19} \mathrm{~F}-\mathrm{NMR}$-based cancer detection along with dendrimer-mediated siRNA therapeutic intervention in cancer treatment. 


\section{A}

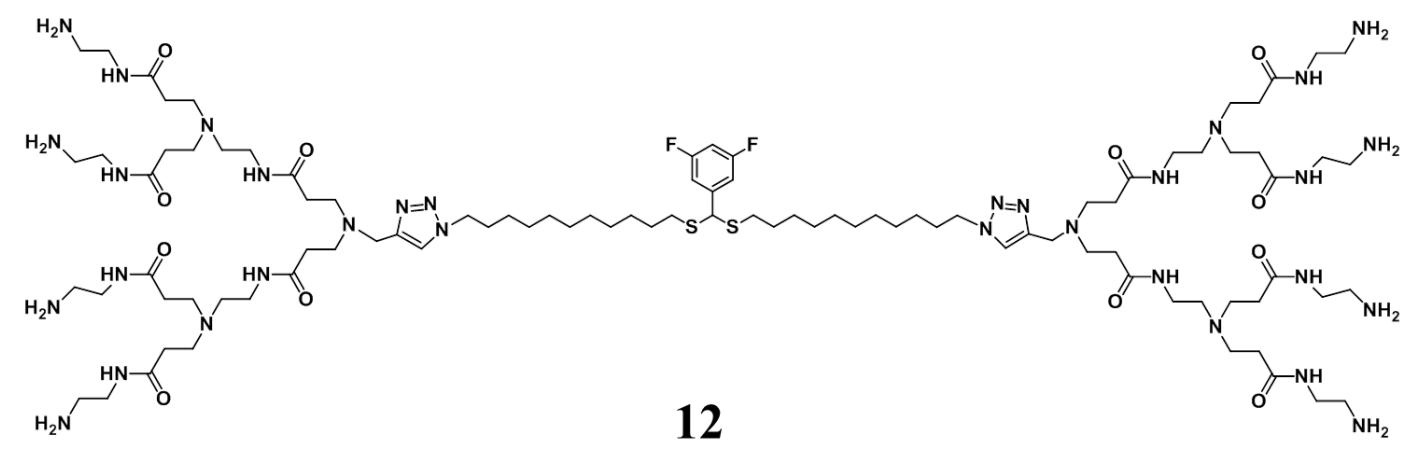

B

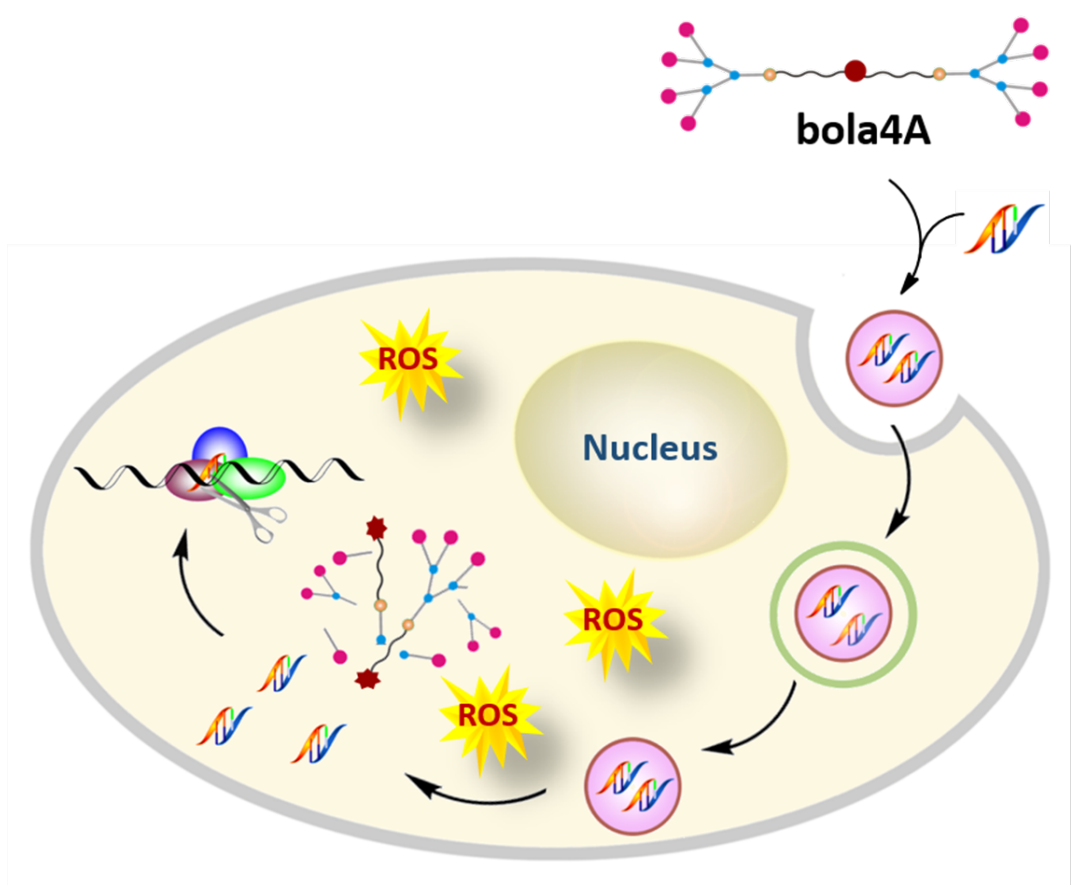

Figure 10: The bola-amphiphilic dendrimer 12 designed for ROS-responsive siRNA delivery. (A) Chemical structure of 12. (B) Schematic representation of 12 for the ROS-triggered delivery of siRNA and consequential gene silencing. The dendrimer $\mathbf{1 2}$ is able to form nanosized complexes with siRNA, which can be internalized by the cancer cell before releasing siRNA in response to ROS, leading to effective gene silencing [49]. 


\section{Conclusion and prospects}

Dendrimers are considered as promising delivery platforms for diverse therapeutic agents because of their distinct molecular architecture, precisely controlled structure and unique multivalence, which is characterized by uniformly-spaced radiating branching units in the interior and multiple terminal groups on the surface. During the last 10 years, dendrimers have emerged as effective nonviral vectors for siRNA delivery. In particular, we have established bio-inspired structurally flexible TEA-core PAMAM dendrimers as excellent vectors for siRNA delivery in various disease models in vitro and in vivo. One of our TEA-core PAMAM dendrimers, namely the generation 5 dendrimer, was scheduled for clinical trial to deliver RNA therapeutics for cancer treatment. Unfortunately, due to the shortage of GMP-standard PAMAM dendrimer, the trial was delayed and finally modified by replacing the dendrimer vector with Smarticles ${ }^{\mathrm{R}}$ as the delivery agent.

To overcome this problem, we have introduced the concept of using small amphiphilic dendrimers to generate self-assembling supramolecular dendrimers, which can mimic covalently-constructed high-generation dendrimers for siRNA delivery. A series of amphiphilic dendrimers have been therefore established and their self-assembling features to generate supramolecular dendrimers for siRNA delivery have been studied. Collectively, our studies have revealed that an optimal balance between the hydrophobic component and the hydrophilic entity is crucial for self-assembly into stable and robust supramolecular dendrimers which can mimic structurally well-defined covalent high-generation dendrimers. These supramolecular assemblies can bind siRNA, shelter it from degradation in the circulation, and release it once internalized within the cell for effective RNA interference and gene silencing. The convenient synthesis of these small amphiphilic dendrimers via click chemistry allows us to carefully devise and gauge building blocks with an ideal hydrophobic/hydrophilic balance in order to identify the best candidates for siRNA delivery. Also, the easy protocol for synthesis of small amphiphilic dendrimers along with the simple purification process will greatly facilitate their eventual GMP production and accelerate their translation into real therapeutic interventions. Therefore, the advent of self-assembling supramolecular dendrimer nanostructures holds great promise and heralds a new era of dendrimer-mediated delivery of RNA therapeutics for 
biomedical applications.

\section{ACKNOWLEDGEMENTS}

We acknowledge support from La Ligue Nationale Contre le Cancer (LP), Fondation pour la Recherche Médicale (SPF20150934261, YC), Association pour la Recherche sur les Tumeurs de la Prostate (LP, XL), Association Française contre les Myopathies (XL), Agence nationale de la Recherche (LP), the international ERA-Net EURONANOMED European Research projects «DENANORNA », «Target4Cancer» and «NANOGLIO»(LP), CNRS, AixMarseille University and China Pharmaceutical University. XL is a distinguished professor of Jiangsu province in China.

\section{REFERENCES:}

(1) Bobbin M L, Rossi J J. RNA interference (RNAi)-based therapeutics: delivering on the promise? Annual Review of Pharmacology and Toxicology, 2016, 56(1): 103-122

(2) Haussecker D, Kay M A. Drugging RNAi. Science, 2015, 347(6226): 1069-1070

(3) Crunkhorn S. Trial watch: pioneering RNAi therapy shows antitumour activity in humans. Nature Reviews: Drug Discovery, 2013, 12(3): 178-178

(4) Castanotto D, Rossi J J. The promises and pitfalls of RNA-interference-based therapeutics. Nature, 2009, 457(7228): 426-433

(5) Fire A, Xu S, Montgomery M K, Kostas S A, Driver S E, Mello C C. Potent and specific genetic interference by double-stranded RNA in Caenorhabditis elegans. Nature, 1998, 391(6669): 806-811

(6) Bernstein E, Caudy A A, Hammond S M, Hannon G J. Role for a bidentate ribonuclease in the initiation step of RNA interference. Nature, 2001, 409(6818): 363-366

(7) Ameres S L, Martinez J, Schroeder R. Molecular basis for target RNA recognition and cleavage by human RISC. Cell, 2007, 130(1): 101-112

(8) Hutvágner G, Zamore P D. A microRNA in a multiple-turnover RNAi enzyme complex. Science, 2002, 297(5589): 2056-2060

(9) Yin H, Kanasty R L, Eltoukhy A A, Vegas A J, Dorkin J R, Anderson D G. Non-viral vectors for genebased therapy. Nature Reviews: Genetics, 2014, 15(8): 541-555

(10) Kanasty R, Dorkin J R, Vegas A, Anderson D. Delivery materials for siRNA therapeutics. Nature Materials, 2013, 12(11): 967-977

(11) Whitehead K A, Langer R, Anderson D G. Knocking down barriers: advances in siRNA delivery. Nature Reviews: Drug Discovery, 2009, 8(2): 129-138

(12) Liu X, Rocchi P, Peng L. Dendrimers as non-viral vectors for siRNA delivery. New Journal of Chemistry, 2012, 36(2): 256-263

(13) Ravina M, Paolicelli P, Seijo B, Sanchez A. Knocking down gene expression with dendritic vectors. Mini-Reviews in Medicinal Chemistry, 2010, 10(1): 73-86

(14) Tomalia D A, Christensen J B, Boas U. Dendrimers, Dendrons, and Dendritic Polymers: Discovery, 
Applications, and the Future. London: Cambridge University Press, 2012, 100-105

(15) Walter M V, Malkoch M. Simplifying the synthesis of dendrimers: accelerated approaches. Chemical Society Reviews, 2012, 41(13): 4593-4609

(16) Tomalia D A B, H.; Dewald, J.; Hall, M.; Kallos, G.; Martin, S.; Roeck, J.; Ryder, J.; Smith, P. A new class of polymers: starburst-dendritic macromolecules. Polymer Journal, 1985, 17(1): 117-132

(17) Haensler J, Szoka F C. Polyamidoamine cascade polymers mediate efficient transfection of cells in culture. Bioconjugate Chemistry, 1993, 4(5): 372-379

(18) Kukowska-Latallo J F, Bielinska A U, Johnson J, Spindler R, Tomalia D A, Baker J R. Efficient transfer of genetic material into mammalian cells using Starburst polyamidoamine dendrimers. Proceedings of the National Academy of Sciences, 1996, 93(10): 4897-4902

(19) Eichman J D, Bielinska A U, Kukowska-Latallo J F, Baker Jr J R. The use of PAMAM dendrimers in the efficient transfer of genetic material into cells. Pharmaceutical Science \& Technology Today, 2000, 3(7): 232245

(20) Guillot-Nieckowski M, Eisler S, Diederich F. Dendritic vectors for gene transfection. New Journal of Chemistry, 2007, 31(7): 1111-1127

(21) Mintzer M A, Simanek E E. Nonviral vectors for gene delivery. Chemical Reviews, 2009, 109(2): 259302

(22) Behr J-P. The proton sponge: a trick to enter cells the viruses did not exploit. CHIMIA International Journal for Chemistry, 1997, 51(1-2): 34-36

(23) Liu X, Liu C, Catapano C V, Peng L, Zhou J, Rocchi P. Structurally flexible triethanolamine-core poly(amidoamine) dendrimers as effective nanovectors to deliver RNAi-based therapeutics. Biotechnology Advances, 2014, 32(4): 844-852

(24) Biswas S, Torchilin V. Dendrimers for siRNA delivery. Pharmaceuticals, 2013, 6(2): 161-183

(25) Kang H, DeLong R, Fisher M H, Juliano R L. Tat-conjugated PAMAM dendrimers as delivery agents for antisense and siRNA oligonucleotides. Pharmaceutical Research, 2005, 22(12): 2099-2106

(26) Zhou J, Wu J, Hafdi N, Behr J-P, Erbacher P, Peng L. PAMAM dendrimers for efficient siRNA delivery and potent gene silencing. Chemical Communications, 2006, 2362-2364

(27) Wu J, Zhou J, Qu F, Bao P, Zhang Y, Peng L. Polycationic dendrimers interact with RNA molecules: polyamine dendrimers inhibit the catalytic activity of Candida ribozymes. Chemical Communications, 2005, 313315

(28) Venkatesh S, Workman J L. Histone exchange, chromatin structure and the regulation of transcription. Nature Reviews: Molecular Cell Biology, 2015, 16(3): 178-189

(29) Liu X, Wu J, Yammine M, Zhou J, Posocco P, Viel S, Liu C, Ziarelli F, Fermeglia M, Pricl S, Victorero G, Nguyen C, Erbacher P, Behr J-P, Peng L. Structurally flexible triethanolamine core PAMAM dendrimers are effective nanovectors for DNA transfection in vitro and in vivo to the mouse thymus. Bioconjugate Chem., 2011, 22(12): 2461-2473

(30) Liu X, Liu C, Laurini E, Posocco P, Pricl S, Qu F, Rocchi P, Peng L. Efficient Delivery of Sticky siRNA and Potent Gene Silencing in a Prostate Cancer Model Using a Generation 5 Triethanolamine-Core PAMAM Dendrimer. Molecular Pharmaceutics, 2012, 9(3): 470-481

(31) Posocco P, Liu X, Laurini E, Marson D, Chen C, Liu C, Fermeglia M, Rocchi P, Pricl S, Peng L. Impact of siRNA overhangs for dendrimer-mediated siRNA delivery and gene silencing. Molecular Pharmaceutics, 2013, 10(8): 3262-3273

(32) Shen X-C, Zhou J, Liu X, Wu J, Qu F, Zhang Z-L, Pang D-W, Quelever G, Zhang C-C, Peng L. Importance of size-to-charge ratio in construction of stable and uniform nanoscale RNA/dendrimer complexes. 
Organic \& Biomolecular Chemistry, 2007, 5(22): 3674-3681

(33) Liu X, Rocchi P, Qu F Q, Zheng S Q, Liang Z C, Gleave M, Iovanna J, Peng L. PAMAM dendrimers mediate siRNA delivery to target Hsp27 and produce potent antiproliferative effects on prostate cancer cells. ChemMedChem., 2009, 4(8): 1302-1310

(34) Liu C, Liu X, Rocchi P, Qu F, Iovanna J L, Peng L. Arginine-terminated generation 4 PAMAM dendrimer as an effective nanovector for functional siRNA delivery in vitro and in vivo. Bioconjugate Chemistry, 2014, 25(3): 521-532

(35) Liu X, Liu C, Chen C, Bentobji M, Cheillan F A, Piana J T, Qu F, Rocchi P, Peng L. Targeted delivery of Dicer-substrate siRNAs using a dual targeting peptide decorated dendrimer delivery system. Nanomedicine: Nanotechnology, Biology and Medicine, 2014, 10(8): 1627-1636

(36) Reebye V, Sætrom P, Mintz P J, Huang K-W, Swiderski P, Peng L, Liu C, Liu X, Lindkær-Jensen S, Zacharoulis D, Kostomitsopoulos N, Kasahara N, Nicholls J P, Jiao L R, Pai M, Spalding D R, Mizandari M, Chikovani T, Emara M M, Haoudi A, Tomalia D A, Rossi J J, Habib N A. Novel RNA oligonucleotide improves liver function and inhibits liver carcinogenesis in vivo. Hepatology, 2014, 59(1): 216-227

(37) Kala S, Mak A S C, Liu X, Posocco P, Pricl S, Peng L, Wong A S T. Combination of dendrimernanovector-mediated small interfering RNA delivery to target akt with the clinical anticancer drug paclitaxel for effective and potent anticancer activity in treating ovarian cancer. Journal of Medicinal Chemistry, 2014, 57(6): 2634-2642

(38) Cui Q, Yang S, Ye P, Tian E, Sun G, Zhou J, Sun G, Liu X, Chen C, Murai K, Zhao C, Azizian K T, Yang L, Warden C, Wu X, D'Apuzzo M, Brown C, Badie B, Peng L, Riggs A D, Rossi J J, Shi Y. Downregulation of TLX induces TET3 expression and inhibits glioblastoma stem cell self-renewal and tumorigenesis. Nature Communications, 2016, 7, 10637-10651

(39) Lang M-F, Yang S, Zhao C, Sun G, Murai K, Wu X, Wang J, Gao H, Brown C E, Liu X, Zhou J, Peng L, Rossi J J, Shi Y. Genome-wide profiling identified a set of miRNAs that are differentially expressed in glioblastoma stem cells and normal neural stem cells. PLoS ONE, 2012, 7(4): e36248-e36251

(40) Zhou J, Neff C P, Liu X, Zhang J, Li H, Smith D D, Swiderski P, Aboellail T, Huang Y, Du Q, Liang Z, Peng L, Akkina R, Rossi J J. Systemic administration of combinatorial dsiRNAs via nanoparticles efficiently suppresses HIV-1 infection in humanized mice. Molecular Therapy, 2011, 19(12): 2228-2238

(41) Svenson S. The dendrimer paradox - high medical expectations but poor clinical translation. Chemical Society Reviews, 2015, 44(12): 4131-4144

(42) Yu T, Liu X, Bolcato-Bellemin A-L, Wang Y, Liu C, Erbacher P, Qu F, Rocchi P, Behr J-P, Peng L. An amphiphilic dendrimer for effective delivery of small interfering RNA and gene silencing in vitro and in vivo. Angewandte Chemie, International Edition in English, 2012, 51(34): 8478-8484

(43) Chen C, Posocco P, Liu X, Cheng Q, Laurini E, Zhou J, Liu C, Wang Y, Tang J, Col V D, Yu T, Giorgio S, Fermeglia M, Qu F, Liang Z, Rossi J J, Liu M, Rocchi P, Pricl S, Peng L. Mastering dendrimer self-Assembly for efficient siRNA delivery: from conceptual design to in vivo efficient gene silencing. Small, 2016, 12(27): 3667-3676

(44) Márquez-Miranda V, Araya-Durán I, Camarada M B, Comer J, Valencia-Gallegos J A, González-Nilo F D. Self-assembly of amphiphilic dendrimers: the role of generation and alkyl chain length in siRNA interaction. Scientific Reports, 2016, 6, 29436-29451

(45) Liu X, Liu C, Zhou J, Chen C, Qu F, Rossi J J, Rocchi P, Peng L. Promoting siRNA delivery via enhanced cellular uptake using an arginine-decorated amphiphilic dendrimer. Nanoscale, 2015, 7(9): 3867-3875

(46) Nakase I, Akita H, Kogure K, Gräslund A, Langel Ü, Harashima H, Futaki S. Efficient intracellular delivery of nucleic acid pharmaceuticals using cell-penetrating peptides. Accounts of Chemical Research, 2012, 
45(7): 1132-1139

(47) Liu X, Zhou J, Yu T, Chen C, Cheng Q, Sengupta K, Huang Y, Li H, Liu C, Wang Y, Posocco P, Wang M, Cui Q, Giorgio S, Fermeglia M, Qu F, Pricl S, Shi Y, Liang Z, Rocchi P, Rossi J J, Peng L. Adaptive amphiphilic dendrimer-based nanoassemblies as robust and versatile siRNA delivery systems. Angewandte Chemie, International Edition in English, 2014, 53(44): 11822-11827

(48) Percec V, Wilson D A, Leowanawat P, Wilson C J, Hughes A D, Kaucher M S, Hammer D A, Levine D H, Kim A J, Bates F S, Davis K P, Lodge T P, Klein M L, DeVane R H, Aqad E, Rosen B M, Argintaru A O, Sienkowska M J, Rissanen K, Nummelin S, Ropponen J. Self-assembly of Janus dendrimers into uniform dendrimersomes and other complex architectures. Science, 2010, 328(5981): 1009-1014

(49) Liu X, Wang Y, Chen C, Tintaru A, Cao Y, Liu J, Ziarelli F, Tang J, Guo H, Rosas R, Giorgio S, Charles L, Rocchi P, Peng, L. A fluorinated bola-amphiphilic dendrimer for on-demand delivery of siRNA, via specific response to reactive oxygen species. Advanced Functional Materials, 2016, DOI: 10.1002/ adfm.201604192.

(50) Gorrini C, Harris I S, Mak T W. Modulation of oxidative stress as an anticancer strategy. Nature Reviews: Drug Discovery, 2013, 12(12): 931-947

(51) Trachootham D, Alexandre J, Huang P. Targeting cancer cells by ROS-mediated mechanisms: a radical therapeutic approach? Nature Reviews: Drug Discovery, 2009, 8(7): 579-591

(52) Valentine D L. Adaptations to energy stress dictate the ecology and evolution of the Archaea. Nature Reviews: Microbiology, 2007, 5, 316-323

(53) Chen H, Viel S, Ziarelli F, Peng L. 19F NMR: a valuable tool for studying biological events. Chemical Society Reviews, 2013, 42(20): 7971-7982 